\title{
Research on Completing Professional Facility System in Teaching Voleyball At Thainguyen University of Economics And Business Administration
}

\author{
Nguyen Ngoc Binh ${ }^{1}$,Duong To Quynh ${ }^{2}$,Nguyen Van Thanh ${ }^{3}$ \\ Thainguyen University Of Economics And Business Administration
}

\begin{abstract}
Summary:Basing on evaluating the current use of professional facilities in teaching volleyball for students at Thainguyen University of Economics and Business Administration - Thainguyen University, the study shows that students' physical education learning result is low; the use of professional facilities in teaching volleyball is not effective; the number of lessons is simple and not suitable for Economics students. From collected results, the research chooses professional facilities of volleyball, which meets the demand of students at TUEBA, contributing to the improvement of students' learning results and physical to study.
\end{abstract}

Keywords:current situation, professional facilities, physical education, Volleyball, Thainguyen University of Economics and Business Administration (TUEBA) - Thainguyen University (TNU)

\section{Rationale For Study}

In teaching and training sports, the use of professional facilities is vital. In order to achieve high score, it is not only based on physical elements, level of learners' training but also the teachers' abilities to use suitable exercises to bring about expected effectiveness. By investigating the use ofprofessional facilities in teaching Volleyball in TUEBA-TNU, the study finds out the inadequate of professional facilities for students at TUEBA. It is one of causes, which limit the effectiveness of the subject for students now. Therefore, "Research on completing professional facility system in volleyball subject of Thainguyen University of Economics and Business Administration" is a scientific matter and practical significance.

\section{Research Methods}

In the researching procedure, we use the following methods: Synthesis and analysis of documents, interview, observation and mathematical statistics [1][2].

\section{Findings And Discussion}

3.1. Current situation of professional facility in teaching volleyball at Thainguyen University of Economics and Business Administration- Thainguyen University

3.1.1. General results of physical education and sport activities of at Thainguyen University of Economics and Business Administration

Physical education division is assigned to teach and organize outside sport activities for students at this university. Annually, the school holds traditional sport prize for all students, among them; football and volleyball are used in competition. Sport club runs regularly and has impact on propagandizing and motoring sport movement of school. However, these sport movements are at medium level; sport teams do not have the high results in competitions held by Ministry of Education and Training.Students' outside sport activities are limited and have not promoted students' self-conscious in doing exercises; physical education results are low.

- Data investigation stored in Physical education Division, we collected physical education learning results of 400 first -year students at TUEBA-TNU in 2015-2016. The results are shown in Table 1:

Table1.Current situation of physical education learning resultsof students at Thainguyen University of Economics and Business Administration

\begin{tabular}{|c|c|c|c|c|c|c|c|}
\hline \multirow{2}{*}{ No. } & \multirow{2}{*}{ Learning result } & \multicolumn{2}{|c|}{ Male (n=100) } & \multicolumn{2}{c|}{ Female (n=300) } & \multicolumn{2}{c|}{ Total } \\
\cline { 3 - 8 } & & Number & $\%$ & number & $\%$ & number & \% \\
\hline 1 & Good & 12 & 12 & 13 & 4,3 & 25 & $\mathbf{6 , 2 5}$ \\
\hline 2 & Fair & 27 & 27 & 79 & 26,3 & 106 & $\mathbf{2 8 , 3}$ \\
\hline 3 & Medium & 41 & 41 & 130 & 43,3 & 171 & $\mathbf{4 3 , 6}$ \\
\hline 4 & Weak & 12 & 12 & 53 & 17,6 & 65 & $\mathbf{2 5 , 5}$ \\
\hline 5 & Bad & 8 & 8 & 25 & 8,3 & 33 & $\mathbf{8 , 2 5}$ \\
\hline
\end{tabular}


Result in table 1 shows that the Good is at low rate $(6.25 \%)$, the Fair $(28.3 \%)$, and the Medium is at the highest rate $(43,6 \%)$, followed by the Weak $(25.5 \%)$ and Bad $(8.25 \%)$. Thus, there are very weak students in the number of student investigated. This proves for the necessity in how to choose professional facilities, which are suitable for students at school, improving students' self-consciousness and activeness.

3.1.2. Professional facilities in teaching volleyball at Thainguyen University of Economics and Business Administration - ThainguyenUniversity

With the aim of evaluating the professional facilities used in teaching volleyball, we carried out observations on over 200 periods and exploited Volleyball outline, lesson plan being used for students. The result of professional facilities used in teaching volleyball is specified as follow.

- Completing technical movement exercises group

1. Pass the ball with two upper hands in front of the face to the wall

2. Pass the ball with two lower hands in front of the face to the wall

3. Contrary pass

4. Contrary accompany

5. Self-throw and hit the ball over the net

6. Serve the ball with upper hand

7. Serve the ball with lower hand

8. Defensive accompany

9. Hitting the hanging ball

- Professional physical exercises group

10. Lying face down and push

11. Jumping rope

12. Skipping jump

Professional facilities used in teaching volleyball at Thainguyen University of Economics and Business Administration - Thainguyen University investigated and listed are 12 exercises. We think that professional facilities are lack in number; the content is simple and not motivating enough for trainees;training exercises only focus on some content such as completing technique and improving physical.

\subsection{Evaluation on the effectiveness of professional facilities in teaching volleyball at Thainguyen University of Economics and Business Administration - Thainguyen University}

In order to evaluate the effectiveness of professional facilities in teaching volleyball, besides the evaluation basing on working experience, we implemented interviews with lecturers in Physical Education Division and students who had studied this subject by questionnaire. The result is presented in table 2.

Table 2: An evaluation on the level of effectiveness of using professional facilities in teaching volleyball at Thainguyen University of Economics and Business Administration - Thainguyen University

\begin{tabular}{|c|c|c|c|c|c|c|c|c|}
\hline \multirow{2}{*}{ Contents } & \multicolumn{9}{|c|}{ Effectiveness } \\
\cline { 2 - 9 } & \multicolumn{2}{|c|}{ Very high } & \multicolumn{2}{|c|}{ High } & \multicolumn{2}{c|}{ Medium } & \multicolumn{2}{c|}{ Low } \\
\hline Parameter & $\mathrm{n}$ & $\%$ & $\mathrm{~N}$ & $\%$ & $\mathrm{n}$ & $\%$ & $\mathrm{n}$ & $\%$ \\
\hline Lecturers $(\mathrm{n}=8)$ & 8 & 0 & 8 & 0 & 4 & 50 & 4 & 50,0 \\
\hline Students $(\mathrm{n}=250)$ & 32 & 12,8 & 35 & 14 & 137 & 66,8 & 46 & 18,4 \\
\hline
\end{tabular}

The result in table 2 shows that the number of students evaluating the effectiveness of volleyball profession facilities is not high, the number of students evaluating the high and very high level is only $28.8 \%$, the medium level is $66.8 \%$, and low level accounts for $18.4 \%$. In addition, the teachers' evaluation directly teaching at physical education division for the effectiveness is only $50 \%$ for both medium and low level. The above results are the exact basis for the objective acknowledgement and assessment of using professional facilities in reality of teaching volleyball at Thainguyen University of Economics and Business Administration, which is not highly effective. The completion for these facilities is necessary.

\subsection{Research on completing professional facilities in Volleyball subject at Thainguyen University of Economics and Business Administration- Thainguyen University.}

Synthetizing domestic and international references [3],[4],[5], counting practical statistics at some universities which share the same economics major, the study determined professional facilities which are able to apply for economic students, they are:

- Completing technical movement exercises group

1. Striking ball continuously to the wall

2. Hitting ball distantly from the net

3 . Hitting ball continuously 
4. Passing ball by 2 hands to the wall

5. Accompanying ball by lower hands

6. Contrary pass

7. Contrary accompany

8. Self-throw and hit the ball over the net

9. Serve the ball with upper hand

10. Serving the ball with lower hand

11. Defensive accompanying and striking

12. Hitting ball from stretch border 2 with passing 2

13. Model hitting with Ante dumbbell

14. Hitting ball stretch border 2

- Professional physical exercises group

15. Hand bending the horizontal bar

Beside the above professional facilities, in the teaching process, lecturers can use other devices such as tourism or sight-seeing if possible.Basing on the above listed professional facilities, we conducted interviews with physical education teachers and administrative staff at TUEBA- TNU to select the professional facilities for Volleyball subject.

The results of interviews are presented in table 3.

From the results shown in table 3, the study is allowedto choose professional facilities, which have more than $50 \%$ completing ideas, and necessary and very necessary ideas at Physical Education Division, in detail:

1. Striking ball continuously to the wall

2. Hitting ball distantly from the net

3. Hitting ball continuously

4. Hitting hanging ball

5. Passing ball by upper hands to the wall

6. Accompanying ball by low hands

7. Contrary pass

8. Contrary accompany

9. Defensive accompanying and striking

10. Serving the ball with upper hand

11. Serving the ball with lower hand

12. Lying face down and push.

13. Jumping rope

14. Throwing the ball over the net

15. Competing

16. Going sight seeing

In short, in the volleyball content, the research chose 16 professional facilities, the other exercises and facilities which have under $50 \%$ agreed ideas are dismissed in experiencing process.

\subsection{Application and evaluation ofthe effectiveness of professional facilities completed in Volleyball.}

In order to assess the effectiveness of selected professional facilities, the study conducted an experiment on 200 first year students at TUEBA-TNU. In experiment process, the two groups studied Volleyball according to the school timetable. Among them, the control group used the current professional facilities; the experiment group used the new professional facilities chosen by this study.

+ Experiment group: there are 100 students, within the group; there are 60 female students and 40 male students.

+ Control group: There are 100 students, among them there are 65 female students and 35 male students.

Table 3: Interview results for completing professional facilities in Volleyball content at TUEBA-TNU.

\begin{tabular}{|c|c|c|c|c|c|c|c|c|}
\hline \multirow{2}{*}{ Professional facilities } & \multicolumn{2}{|c|}{$\begin{array}{l}\text { Number of chosen } \\
\text { ideas }\end{array}$} & \multicolumn{6}{|c|}{ Level of completion } \\
\hline & \multirow{2}{*}{$\begin{array}{c}\mathbf{n} \\
23\end{array}$} & \multirow{2}{*}{$\begin{array}{c}\% \\
71,87\end{array}$} & \multicolumn{2}{|c|}{ Very necessary } & \multicolumn{2}{|c|}{ Nescessary } & \multicolumn{2}{|c|}{ Unnecessary } \\
\hline $\begin{array}{l}\text { 1. Striking ball continuously to the } \\
\text { wall }\end{array}$ & & & 15 & 65,2 & 7 & 30,5 & 1 & 4,3 \\
\hline 2. Hitting ball distantly from the net & 25 & 78,1 & 5 & 20,0 & 20 & 80,0 & 0 & 0 \\
\hline 3. Hitting ball continuously & 27 & 84,37 & 21 & 77,7 & 6 & 22,3 & 0 & 0 \\
\hline 4. Passing ball by upper hands to the wall & 31 & 96,87 & 25 & 80,64 & 6 & 19,36 & 0 & 0 \\
\hline 5. Accompanying ball by lower hands & 32 & 100 & 32 & 100 & 0 & 0 & 0 & 0 \\
\hline 6. Contrary pass & 30 & 93,75 & 20 & 66,6 & 10 & 33,4 & 0 & 0 \\
\hline 7. Contrary accompany & 28 & 87,5 & 19 & 67,85 & 7 & 25,0 & 2 & 7,15 \\
\hline 8. Self-throw and hit the ball over the net & 14 & 43,75 & 5 & 35,71 & 4 & 28,57 & 5 & 35,71 \\
\hline 9. Serving the ball with upper hand & 28 & 87,5 & 20 & 71,42 & 8 & 28,58 & 0 & 0 \\
\hline
\end{tabular}


Research On Completing Professional Facility System In Teaching Voleyball...

\begin{tabular}{|l|c|c|c|c|c|c|c|c|}
\hline 10. Serving the ball with lower hand & 26 & 81,25 & 18 & 69,23 & 5 & 19,23 & 3 & 11,54 \\
\hline 11. Defensive accompanying and striking & 27 & 84,37 & 21 & 65,56 & 8 & 28,58 & 0 & 0 \\
\hline $\begin{array}{l}\text { 12. Hitting ball from stretch border 2 } \\
\text { with passing 2 }\end{array}$ & 10 & 31,25 & 0 & 0 & 5 & 50,0 & 5 & 50,0 \\
\hline 13. Model hitting with Ante dumbbell & 5 & 15,62 & 0 & 0 & 5 & 100 & 0 & 0 \\
\hline $\begin{array}{l}\text { 14. Hitting ball from stretch border } \\
\text { with other techniques }\end{array}$ & 14 & 43,75 & 4 & 28,5 & 10 & 71,5 & 0 & 0 \\
\hline 15. Hitting hanging ball & 22 & 68,75 & 4 & 50 & 3 & 37,5 & 1 & 12,5 \\
\hline 16. Hand bending the horizontal bar & 5 & 15,62 & 0 & 0 & 3 & 60 & 2 & 40 \\
\hline 17. Lying face down and push & 28 & 87,5 & 19 & 67,85 & 7 & 25,0 & 2 & 7,15 \\
\hline 18. Jumping rope & 27 & 84,37 & 21 & 77,7 & 6 & 22,3 & 0 & 0 \\
\hline 19. rebounding into sandy hole & 12 & 37,5 & 6 & 50 & 6 & 50 & 0 & 0 \\
\hline 20. Throw ball over the net & 28 & 87,5 & 20 & 71,42 & 8 & 28,58 & 0 & 0 \\
\hline 21. Skipping jump & 14 & 43,75 & 0 & 0 & 4 & 28,5 & 10 & 71,5 \\
\hline $\begin{array}{l}\text { 22. Hitting ball over the people-defensive } \\
\text { net }\end{array}$ & 7 & 21,87 & 6 & 85,71 & 1 & 14,29 & 0 & 0 \\
\hline 23. Hitting ball to score & 9 & 28,12 & 3 & 33,3 & 3 & 33,3 & 3 & 33,3 \\
\hline 24. Competing & 27 & 84,37 & 21 & 77,7 & 6 & 22,3 & 0 & 0 \\
\hline 25. Going sightseeing & 30 & 93,75 & 20 & 66,6 & 10 & 33,4 & 0 & 0 \\
\hline 26. Travelling & 8 & 25,0 & 1 & 12,5 & 3 & 37,5 & 4 & 50 \\
\hline
\end{tabular}

Table 4: Assessing male students' physical in control and experiment groups before the experiment

\begin{tabular}{|c|l|c|c|c|c|c|c|}
\hline \multirow{2}{*}{ No. } & \multicolumn{1}{|c|}{ Content } & \multicolumn{2}{c|}{$\begin{array}{c}\text { Experimental group } \\
(\mathbf{n = 4 0})\end{array}$} & \multicolumn{2}{c|}{$\begin{array}{c}\text { Control group } \\
(\mathbf{n}=\mathbf{3 5})\end{array}$} & \multirow{2}{*}{$\mathbf{t}$} & \multirow{2}{*}{$\mathbf{p}$} \\
\cline { 3 - 6 } & & $\bar{X}$ & $\pm \delta$ & $\bar{X}$ & $\pm \delta$ & & \\
\hline 1 & $\begin{array}{l}\text { Preferred hand squeeze force } \\
\text { (KG) }\end{array}$ & 43,12 & 3.15 & 42,63 & 2,45 & 0,28 & $>0,05$ \\
\hline 2 & $\begin{array}{l}\text { Lying face up and bending belly } \\
\text { (times/30s) }\end{array}$ & 20,56 & 2,83 & 20,69 & 2,43 & 0,62 & $>0,05$ \\
\hline 3 & Rebounding on the spot (cm) & 221 & 16,43 & 223 & 16,87 & 0,24 & $>0,05$ \\
\hline 4 & $\begin{array}{l}\text { Running 30m with upper starting } \\
\text { point (s) }\end{array}$ & 5,58 & 0,47 & 5,53 & 0,50 & 0,47 & $>0,05$ \\
\hline 5 & Shuttle running 4x10m (s) & 12,45 & 1,30 & 12,38 & 0,66 & 0,35 & $>0,05$ \\
\hline 6 & Running depending on health (m) & 1005 & 244 & 1008 & 272 & 0,80 & $>0,05$ \\
\hline
\end{tabular}

Table 5: Assessing female students' physical in control and experiment groups before the experiment

\begin{tabular}{|c|c|c|c|c|c|c|c|}
\hline \multirow{2}{*}{ No. } & \multirow{2}{*}{ Content } & \multicolumn{2}{|c|}{$\begin{array}{l}\text { Experimental group } \\
(\mathrm{n}=60)\end{array}$} & \multicolumn{2}{|c|}{$\begin{array}{c}\text { Control group } \\
(\mathrm{n}=65)\end{array}$} & \multirow{2}{*}{$\mathrm{t}$} & \multirow{2}{*}{$\mathrm{p}$} \\
\hline & & $X$ & $\pm \delta$ & $\bar{X}$ & $\pm \delta$ & & \\
\hline 1 & $\begin{array}{l}\text { Preferred hand squeeze } \\
\text { force }(\mathrm{KG})\end{array}$ & 26,27 & 2,32 & 26,44 & 2,49 & 0,66 & $>0,05$ \\
\hline 2 & $\begin{array}{l}\text { Lying face up and bending } \\
\text { belly (times/30s) }\end{array}$ & 16,32 & 3,15 & 16,49 & 3,16 & 0,56 & $>0,05$ \\
\hline 3 & $\begin{array}{l}\text { Rebounding on the spot } \\
(\mathrm{cm})\end{array}$ & 153,2 & 9,93 & 155,8 & 8,60 & 0,75 & $>0,05$ \\
\hline 4 & $\begin{array}{l}\text { Running } 30 \mathrm{~m} \text { with upper } \\
\text { starting point }(\mathrm{s})\end{array}$ & 6,68 & 0,70 & 6,64 & 0,72 & 0,35 & $>0,05$ \\
\hline 5 & Shuttle running $4 \times 10 \mathrm{~m}(\mathrm{~s})$ & 13,06 & 1,32 & 13,04 & 1,23 & 0,29 & $>0,05$ \\
\hline 6 & $\begin{array}{l}\text { Running depending on } \\
\text { health within } 5 \text { minutes }(\mathrm{m})\end{array}$ & 864 & 62,8 & 863 & 64,8 & 0,65 & $>0,05$ \\
\hline
\end{tabular}

Table 6: Learning Physical Education results of control and experimental group before the experiment

\begin{tabular}{|c|c|c|c|c|c|c|c|}
\hline \multirow{2}{*}{ No. } & \multirow{2}{*}{ Learning outcome } & \multicolumn{2}{|c|}{$\begin{array}{c}\text { Experimental group } \\
(\mathbf{n = 1 0 0})\end{array}$} & \multicolumn{2}{c|}{$\begin{array}{c}\text { Control group } \\
(\mathbf{n = 1 0 0})\end{array}$} & \multirow{2}{*}{$\mathbf{X}^{\mathbf{2}}$} & \multirow{2}{*}{$\mathbf{P}$} \\
\cline { 3 - 6 } & & $\mathrm{n}$ & $\mathrm{n}$ & $\%$ & $\%$ & & \\
\hline 1 & Good & 12 & 12 & 11 & 11 & \\
\hline 2 & Fair & 28 & 28 & 26 & 26 & \multirow{3}{*}{3,714} & $>0,05$ \\
\hline 3 & Medium & 35 & 35 & 38 & 38 & & \\
\hline 4 & Weak & 17 & 17 & 16 & 16 & & \\
\hline 5 & Bad & 8 & 8 & 9 & 9 & & \\
\hline
\end{tabular}




\section{Evaluation of physical and learning result of control and experimental groups before experiment.}

The figures in table 4 and 5 shows that, the above physical index of all 6 contents is $t_{\text {tính }}<\mathrm{t}_{\text {bảng. }}$. Therefore, male and female physical in both control and experimental groups are equal, the difference is not meaningful in statistics with $p>0.05$. The result in table 6 indicates that, the learning result of both groups is quite the same with $\mathrm{X} 2=3.714, \mathrm{p}>0.05$.

Evaluation of experiment effectiveness of professional facilities to physical and learning results of control and experimental group after experiment

The physical assessment result of experimental group.

The research assessed the before and after experiment results of male and female students of experimental groups. According to table 7 and 8, the results show that there are 3 criteria of both male and female groups increasing for more than $5 \%$, the left criteria raise above $2 \%$. Compare the increasing level of before and after experiment of students in experimental group through t-student index, it is indicated that there is a difference in statistic meaning with $\mathrm{p}<0.05$. Thus, after learning the new programme, the experimental group has a higher level in physical in comparison with the beginning. This proves for the effectiveness of selected professional facilities.

Table 7: Evaluate male physical in experimental group before and after experiment.

\begin{tabular}{|c|c|c|c|c|c|c|c|c|}
\hline \multirow{3}{*}{ No. } & \multirow{3}{*}{ Content } & \multicolumn{7}{|c|}{ Male $(n=40)$} \\
\hline & & \multicolumn{2}{|c|}{ Pre-experiment } & \multicolumn{2}{|c|}{ Post-experiment } & \multirow{2}{*}{$\mathbf{t}$} & \multirow{2}{*}{$\begin{array}{l}\mathbf{W} \\
\%\end{array}$} & \multirow{2}{*}{$\mathbf{p}$} \\
\hline & & $\bar{X}$ & $\pm \delta$ & $\bar{X}$ & $\pm \delta$ & & & \\
\hline 1 & $\begin{array}{l}\text { Preferred hand squeeze } \\
\text { force }(K G)\end{array}$ & 43,12 & 3.15 & 43,65 & 3.47 & 5,07 & 4,6 & $<0,05$ \\
\hline 2 & $\begin{array}{l}\text { Lying face up and bending } \\
\text { belly (times } 30 \mathrm{~s} \text { ) }\end{array}$ & 20,56 & 2,83 & 23,36 & 2,85 & 5,97 & 10,2 & $<0,05$ \\
\hline 3 & $\begin{array}{l}\text { Rebounding on the spot } \\
(\mathrm{cm})\end{array}$ & 221 & 16,43 & 228 & 15,83 & 7,86 & 3,1 & $<0,05$ \\
\hline 4 & $\begin{array}{l}\text { Running } 30 \mathrm{~m} \text { with upper } \\
\text { starting point }(\mathrm{s})\end{array}$ & 5,58 & 0,47 & 5,02 & 0,65 & 3,45 & 10,5 & $<0,05$ \\
\hline 5 & Shuttle running $4 \mathrm{x} 10 \mathrm{~m}(\mathrm{~s})$ & 12,45 & 1,30 & 11,60 & 0,74 & 3,81 & 6,9 & $<0,05$ \\
\hline \multirow[t]{2}{*}{6} & $\begin{array}{l}\text { Running depending on } \\
\text { health within } 5 \text { minutes }(\mathrm{m})\end{array}$ & 1005 & 244 & 1020 & 95 & 7,58 & 2,6 & $<0,05$ \\
\hline & \multicolumn{6}{|l|}{ 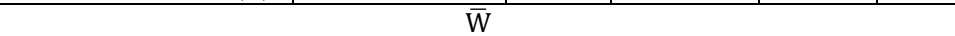 } & 6,31 & \\
\hline
\end{tabular}

Table 8: Evaluate female physical in experimental group before and after experiment.

\begin{tabular}{|c|c|c|c|c|c|c|c|c|}
\hline \multirow{3}{*}{ No. } & \multirow{3}{*}{ Content } & \multicolumn{7}{|c|}{ Female $(n=60)$} \\
\hline & & \multicolumn{2}{|c|}{ Pre-experiment } & \multicolumn{2}{|c|}{ Post-experiment } & \multirow{2}{*}{$\mathbf{t}$} & \multirow{2}{*}{ W\% } & \multirow{2}{*}{$\mathbf{p}$} \\
\hline & & $X$ & $\pm \delta$ & $X$ & $\pm \delta$ & & & \\
\hline 1 & $\begin{array}{l}\text { Preferred hand squeeze force } \\
\text { (KG) }\end{array}$ & 26,27 & 2,32 & 27,75 & 2,29 & 5,81 & 5,7 & $<0,05$ \\
\hline 2 & $\begin{array}{l}\text { Lying face up and bending } \\
\text { belly (times/30s) }\end{array}$ & 16,32 & 3,15 & 18,07 & 3,54 & 5,31 & 6,4 & $<0,05$ \\
\hline 3 & Rebounding on the spot $(\mathrm{cm})$ & 153,2 & 9,93 & 156,6 & 8,52 & 6,12 & 2,3 & $<0,05$ \\
\hline 4 & $\begin{array}{l}\text { Running 30m with upper } \\
\text { starting point (s) }\end{array}$ & 6,68 & 0,70 & 6,11 & 0,65 & 4,01 & 7,5 & $<0,05$ \\
\hline 5 & Shuttle running $4 \times 10 \mathrm{~m}(\mathrm{~s})$ & 13,06 & 1,32 & 12,51 & 1,05 & 3,05 & 4,7 & $<0,05$ \\
\hline \multirow[t]{2}{*}{6} & $\begin{array}{l}\text { Running depending on } \\
\text { health within } 5 \text { minutes }(\mathrm{m})\end{array}$ & 864 & 62,8 & 877 & 55,8 & 9,28 & 2,6 & $<0,05$ \\
\hline & \multicolumn{5}{|c|}{$\overline{\mathrm{W}}$} & & 4,68 & \\
\hline
\end{tabular}

\section{Results Of Physical Examination In The Control Group}

The results of the physical examination of the control group are presented in Table 9 and 10 . Experimental groups also showed growth in all 6 indicators, of which 2 indicators of male and female are $3 \%$ higher, the remaining indicators are below 3\%. Average growth rate of the control group in male is $1.84 \%$, and in female is $1.87 \%$. Comparison of the improvement of the pre-experiment versus post-experiment score obtained by the t-student showed that only three indicators were: forward pushing, abdominal flexion, and 5minute run in male and preferred hand squeeze force, rebounding on the spot, running depending on female capacity within 5 minutes female capacity is statistically significant with $\mathrm{p}<0.05$. The remaining indicators in both male and female, however, show progressive but only random, with $p>0.05$. Thus, after the completion of the new program the control group was able to progress but still low, which proved that the current professional facilities of the school have not been fully effective in improving physical fitness for school students. 
Research On Completing Professional Facility System In Teaching Voleyball...

Table 9. Pre- and post- experiment evaluation on male physical of the control group

\begin{tabular}{|c|c|c|c|c|c|c|c|c|}
\hline \multirow{3}{*}{ No. } & \multirow{3}{*}{ Content } & \multicolumn{7}{|c|}{ Male $(n=35)$} \\
\hline & & \multicolumn{2}{|c|}{ Pre-experiment } & \multicolumn{2}{|c|}{ Pre-experiment } & \multirow{2}{*}{$\mathbf{t}$} & \multirow{2}{*}{ W\% } & \multirow[b]{2}{*}{$\mathbf{p}$} \\
\hline & & $X$ & $\pm \delta$ & $X$ & $\pm \delta$ & & & \\
\hline 1 & $\begin{array}{l}\text { Preferred hand squeeze } \\
\text { force (KG) }\end{array}$ & 42,63 & 2,45 & 42,72 & 2,48 & 2,40 & 2,2 & $<0,05$ \\
\hline 2 & $\begin{array}{l}\text { Lying face up and } \\
\text { bending belly (times/30s) }\end{array}$ & 20,69 & 2,43 & 22,15 & 2,78 & 2,89 & 5,1 & $<0,05$ \\
\hline 3 & $\begin{array}{l}\text { Rebounding on the spot } \\
(\mathrm{cm})\end{array}$ & 223 & 16,87 & 223 & 15,50 & 1,05 & 0,5 & $>0,05$ \\
\hline 4 & $\begin{array}{l}\text { Running 30m with upper } \\
\text { starting point (s) }\end{array}$ & 5,53 & 0,50 & 5,41 & 0,72 & 0,64 & 2,1 & $>0,05$ \\
\hline 5 & $\begin{array}{l}\text { Shuttle running } 4 \times 10 \mathrm{~m} \\
\text { (s) }\end{array}$ & 12,38 & 0,66 & 12,22 & 0,85 & 0,64 & 1,6 & $>0,05$ \\
\hline 6 & $\begin{array}{l}\text { Running depending on } \\
\text { health within } 5 \\
\text { minutes }(\mathrm{m})\end{array}$ & 1008 & 272 & 1014 & 105 & 2,85 & 0,7 & $<0,05$ \\
\hline & & & $\overline{\mathrm{W}}$ & & & & 1,84 & \\
\hline
\end{tabular}

Table 10. Pre - and post - experiment evaluation on female physical of the control group

\begin{tabular}{|c|c|c|c|c|c|c|c|c|}
\hline \multirow{3}{*}{ No. } & \multirow{3}{*}{ Content } & \multicolumn{7}{|c|}{ Female $(n=65)$} \\
\hline & & \multicolumn{2}{|c|}{ Pre-experiment } & \multicolumn{2}{|c|}{ Pre-experiment } & \multirow{2}{*}{$\mathbf{t}$} & \multirow{2}{*}{ W\% } & \multirow{2}{*}{$\mathbf{p}$} \\
\hline & & $X$ & $\pm \delta$ & $X$ & $\pm \delta$ & & & \\
\hline 1 & $\begin{array}{l}\text { Preferred hand squeeze force } \\
\text { (KG) }\end{array}$ & 26,44 & 2,49 & 27,08 & 2,01 & 2,65 & 2,3 & $<0,05$ \\
\hline 2 & $\begin{array}{l}\text { Lying face up and bending } \\
\text { belly (times } / 30 \mathrm{~s} \text { ) }\end{array}$ & 16,49 & 3,16 & 16,79 & 3,55 & 1,33 & 2,4 & $>0,05$ \\
\hline 3 & $\begin{array}{l}\text { Rebounding on the spot } \\
(\mathrm{cm})\end{array}$ & 155,8 & 8,60 & 154,2 & 8,09 & 4,2 & 1,5 & $<0,05$ \\
\hline 4 & $\begin{array}{l}\text { Running } 30 \mathrm{~m} \text { with upper } \\
\text { starting point (s) }\end{array}$ & 6,64 & 0,72 & 6,43 & 0,66 & 1,48 & 3,3 & $>0,05$ \\
\hline 5 & Shuttle running $4 \times 10 \mathrm{~m}(\mathrm{~s})$ & 13,04 & 1,23 & 12,90 & 1,12 & 0,31 & 1,2 & $>0,05$ \\
\hline \multirow[t]{2}{*}{6} & $\begin{array}{l}\text { Running depending on } \\
\text { health within } 5 \text { minutes }(\mathrm{m})\end{array}$ & 863 & 64,8 & 865 & 63,0 & 4,28 & 0,9 & $<0,05$ \\
\hline & \multicolumn{6}{|l|}{ 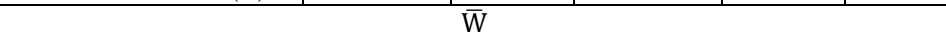 } & 1,87 & \\
\hline
\end{tabular}

* Evaluate the growth rate of the control group and the experimental group after the experiment.

Based on the results of the growth rate obtained in Tables 7.8, 9 and 10, the research was conducted to evaluate the growth rate of the male in control group and male in experimental group after experiment. Results are in Table 11

Table 11. The growth rate of the male in control group and male in experimental group after experiment

\begin{tabular}{|c|c|c|c|c|c|c|c|c|}
\hline \multirow{3}{*}{ No. } & \multirow{3}{*}{ Content } & \multirow{2}{*}{\multicolumn{2}{|c|}{ Experimental group }} & \multirow{2}{*}{\multicolumn{2}{|c|}{ Control group }} & \multicolumn{3}{|c|}{ Comparison } \\
\hline & & & & & & \multicolumn{2}{|c|}{ Times } & $\mathbf{S}_{(-)}$ \\
\hline & & Male & Female & Male & Female & Male & Female & \\
\hline 1 & $\begin{array}{l}\text { Preferred hand squeeze } \\
\text { force }(\mathrm{KG})\end{array}$ & 4,6 & 5,7 & 2,2 & 2,3 & 2,2 & 2,4 & \multirow{6}{*}{0} \\
\hline 2 & $\begin{array}{l}\text { Lying face up and } \\
\text { bending belly (times } / 30 \text { s) }\end{array}$ & 10,2 & 6,4 & 5,1 & 2,4 & 2,1 & 2,7 & \\
\hline 3 & $\begin{array}{l}\text { Rebounding on the spot } \\
(\mathrm{cm})\end{array}$ & 3,1 & 2,3 & 0,5 & 1,5 & 7,75 & 1,7 & \\
\hline 4 & $\begin{array}{l}\text { Running } 30 \mathrm{~m} \text { with upper } \\
\text { starting point (s) }\end{array}$ & 10,5 & 7,5 & 2,1 & 3,3 & 5,25 & 2,2 & \\
\hline 5 & $\begin{array}{l}\text { Shuttle running } 4 \times 10 \mathrm{~m} \\
\text { (s) }\end{array}$ & 6,9 & 4,7 & 1,6 & 1,2 & 5,3 & 4,2 & \\
\hline 6 & $\begin{array}{l}\text { Running depending on } \\
\text { health within } 5 \\
\text { minutes(m) }\end{array}$ & 2,6 & 2,6 & 0,7 & 0,9 & 5,2 & 3,6 & \\
\hline & $\bar{W}$ & 6,31 & 4,77 & 1,88 & 4,68 & 2,2 & 2,6 & 0 \\
\hline
\end{tabular}


The results in Table 11 show that all the physical indexes of both experimental and control male groups showed a remarkable growth. However, growth in the control group was stronger, at least $2.6 \%$ (Running depending on health within 5 minutes) and at most $10.5 \%$ (running 30m with upper starting point) and an average of 6 , $31 \%$. Meanwhile, the growth rate in the control group was weaker, at least $0.4 \%$ (rebounding on the spot) and at most $5 \%$ (Lying face up and bending belly), on average $1.88 \%$. The results showed that the growth rate of the experimental group in all surveyed subjects is more than the control group from 2.1 times to 7.75 times, averaging 3.36 times. Comparing the growth rate of the two groups through the $\mathrm{S}$ indicator [5], when viewing each content as an individual, it shows that $\mathrm{S}(-)=0=\mathrm{S} 0.05=0$, it proves that the more or less of growth rate is statistically significant with probability $\mathrm{p}=0.05$. For experimental and control female groups, there was a growth. However, growth in female empirical groups was more prominent, at least in the rebounding on the spot $(2.3 \%)$ and at the highest is in the running $30 \mathrm{~m}$ with upper starting point $(7.5 \%)$, on average of $4.77 \%$. Meanwhile, the growth rate in the control group was fainter, running depending on health within 5 minutes was the lowest $(0.9 \%)$, and the highest is in the $30 \mathrm{~m}$ running with high start $(3.3 \%)$, on the average of $4.68 \%$. The results also showed that the growth rate of the experimental group in all surveyed subjects was higher than the control group from1.7 times to 4.2 times, the average increase of 2.6 times. Comparing the growth rate of the two groups through the $S$ indicator when viewing each content as an individual, showed that $S(-)=0=S 0.05=0$. It proves that the more or less of growth rate is statistically significant with probability $\mathrm{p}=0.05$

* Evaluation of learning outcomes

The study evaluates the quality of learning outcomes of the groups according to final test scores after the experiment. The results are presented in tables 12,13 .

Table 12. Learning outcome results of Volleyball ater experiment of control and experimental group

\begin{tabular}{|c|l|c|c|c|c|}
\hline \multirow{2}{*}{ No. } & \multirow{2}{*}{ Learning outcome } & \multicolumn{2}{|c|}{ Control group $(\mathbf{n = 1 0 0})$} & \multicolumn{2}{c|}{ Experimental group $(\mathbf{n = 1 0 0})$} \\
\cline { 3 - 6 } & & \multicolumn{2}{|c|}{ Post- experiment } & \multicolumn{2}{c|}{ Post experiment } \\
\cline { 3 - 6 } & & $\mathbf{n}$ & $\boldsymbol{n}$ & $\mathbf{n}$ \\
\hline 1 & Good & 15 & 15 & 18 & 18 \\
\hline 2 & Fair & 35 & 35 & 46 & 46 \\
\hline 3 & Medium & 40 & 40 & 32 & 4 \\
\hline 4 & Weak & 7 & 7 & 1 & 0 \\
\hline 5 & Bad & 3 & 3 & 3 & 4 \\
\hline
\end{tabular}

Table 13.Comparison of learning outcome of control and experiment group though good and weak students

\begin{tabular}{|c|c|c|c|c|c|}
\hline \multirow{2}{*}{ No. } & \multirow{2}{*}{ Learning outcome } & \multirow{2}{*}{ Control group } & \multirow{2}{*}{ Experimental group } & \multicolumn{2}{|c|}{ comparison } \\
\cline { 5 - 6 } & & & & $\mathbf{X}^{2}$ & P \\
\hline 1 & Good & 15 & 18 & 3,08 & $<0,05$ \\
\hline
\end{tabular}

The results in Table 12 show that the average and fair rankings of the two groups are almost equal. Therefore, we need to analyze in depth the number of good students and weak students between the experimental and control groups to see whether the two groups are different. The results of the analysis presented in Table 13 indicate that the experimental group had significantly better numbers and that the control group had significantly lower numbers and that it was statistically significant with probability $\mathrm{p}<0.05$. In summary, from the above results, it is shown that the use of professional facilities that the study has selected and tested has had a positive impact on the quality of learning Volleyball at Thai Nguyen University of Economics And Business Administration - Thai Nguyen University.

\section{Conclusion}

The actual use of professional facilities in teaching volleyball is inadequate, affecting the quality of teaching physical education. Especially, the specialized facilities are still monotonous, lack of rationality and efficiency.Through the resources and interviews, the research has selected to complete 16 professional facilities of Volleyball. These facilities include physical exercises, sports, motorized games, sightseeing and travel.The effectiveness of the professional facility system of volleyball was improved and tested in practice with statistical reliability at the probability level of $\mathrm{P}<0.05$, which resulted in improved performance of study and physical fitness of school students. 


\section{References}

[1]. Nguyen Duc Van (2000).Statistical methods in Sports.Hanoi: Sports Publishing House.

[2]. Nguyen XuanSinh, Le Van Lam, LuuQuangHiep and Pham Ngoc Vien (2006).Curriculum ScientificResearch Sport.Hanoi: Sports Publishing House.

[3]. Nguyen Ngoc Long (2015).Volleyball Textbook.Hanoi: Information and Communication Publishing House.

[4]. Physical education programs in Universities, colleges (non-specialized DTT) stage II(1997). Issued under Decision No. 1262 / QD / BGDDT dated April 12, 1997.

[5]. Dinh Van Lam, Pham TheVuong (2006). Volleyball Textbook.Hanoi: Sports Publishing House.

[6]. Duong DuongNghiep et al. (2006). Sports Measurement. Hanoi: Sports Publishing House 